\title{
Rancang Bangun Aplikasi E-Voting Multi Instansi Berbasis Web Dengan QR Code
}

\section{Design and Build a Web-based Multi-Agency E-Voting Application with QR Code}

\author{
Mohamad Anas Sobarnas ${ }^{1 *}$, Pria Sukamto1, Yosep Nuryaman² \\ ${ }^{1 *}$ Program Studi Teknik Informatika, Sekolah Tinggi Teknologi Muhammadiyah Cileungsi-Indonesia \\ 2 Program Studi Sistem Informatika, Universitas Bina Sarana Informatika-Indonesia \\ $1^{*}$ Jln. Anggrek No.25 Komplek Perum PTSC, Cileungsi, Bogor, Jawa Barat-Indonesia 16820 \\ 2 Jl. Ciledug Raya No.168, RW.4, Ulujami, Kec. Pesanggrahan, Kota Jakarta Selatan, Daerah Khusus Ibukota \\ Jakarta-Indonesia 12250
}

Informasi Artikel

Article History:

Submission: 05-12-2021

Revised: 14-12-2021

Accepted: 17-12-2021

\section{Kata Kunci:}

Pemilihan; e-Voting; QR Code; VB Net; Aplikasi Web

\section{Keywords:}

Election; e-Voting; QR Code; VB Net; Web Application

\section{* Korespondensi:}

Mohamad Anas Sobarnas anassobarnas87@gmail.com

\begin{abstract}
Abstrak
Beberapa permasalahan dan kelemahan pemilihan yang dilaksanakan secara manual adalah lamanya proses pemilihan, perhitungan suara dan membutuhkan biaya yang lumayan besar untuk cetak kertas suara, menyiapkan kotak suara, hingga harus menyediakan alat perhitungan. E-voting adalah jawaban untuk permasalahan tersebut, beberapa keuntungan diantaranya mempercepat proses pemilihan, akurasi, efisiensi biaya dan waktu. Aplikasi dibangun berbasis Web Application menggunakan pemrograman VB Net dengan database SQL Server. Aplikasi dirancang agar bisa melakukan dua jenis pemilihan, ketua (perorangan) atau formatur (kelompok), selain itu aplikasi juga dirancang agar bisa diakses secara multi instansi, ini bertujuan agar aplikasi bisa terus dipakai oleh seluruh pihak yang membutuhkan dan untuk menjaga keamanan digunakan fasilitas QR-Code. Hasil dari penelitian ini berupa aplikasi pemilihan berbasis web, adapun kuisioner berdasarkan kepuasan pengguna mendapatkan hasil $82 \%$ sangat baik dan $18 \%$ baik.
\end{abstract}




\section{PENDAHULUAN.}

Setiap organisasi atau instansi pasti akan melaksanakan perubahan pengurus atau struktur sebagaimana aturan instansi tersebut. Salah satu cara perubahan struktur dalam sebuah organisasi adalah dengan melakukan pemilihan (voting). Di era kemajuan teknologi pemilihan bisa dipermudah dengan melakukan e-voting (electronic voting)[1][2][3]. Hal ini dapat memberikan manfaat lebih di antaranya, proses lebih cepat, validasi suara tidak sah (human error) [4], akurasi data [5], biaya lebih efisien [6] serta beberapa keuntungan lainnya.

Permasalahan utama pada proses e-voting adalah trash (kepercayaan)[7] dari pemilih kepada pihak panitia penyelenggara akan kerahasiaan suara yang dipilih[8]. Permasalahan tersebut dapat dikurangi dengan cara menggunakan $Q R$ Code[9], setiap peserta (pemilih) akan diberikan Print QR Code secara acak dan pada saat akan melaksanakan proses pemilihan pemilih tinggal membuka aplikasi dan melakukan scan $Q R$ Code tersebut[10]. Dengan demikian maka kerahasiaan akan tetap terjaga karena panitia pun tidak akan mengetahui siapa memilih kandidat yang mana. Selain itu akan mempercepat proses login karena tidak perlu memasukan username dan password.

Tujuan dari penelitian ini adalah adanya aplikasi $e$-voting berbasis Web dengan $Q R$ Code [11] yang akan dibangun menggunakan aplikasi VB Net [12] dengan database SQL Server [13]. Aplikasi ini akan mempermudah proses pemilihan suara khususnya pada Perguruan Muhammadiyah Cileungsi dan umumnya bagi seluruh masyarakat yang membutuhkan percepatan dan akurasi proses pemilihan.

\section{METODE}

Metode yang digunakan untuk perancangan aplikasi pada penelitian ini adalah Waterfall Model [14][15], dengan tahapan sebagai berikut:

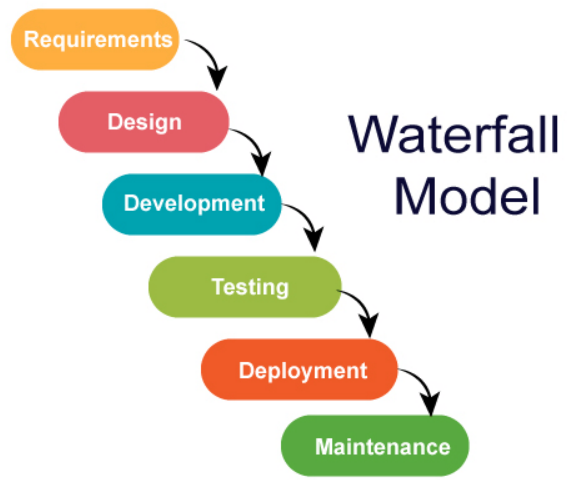

Gambar 1. Waterfall model process [14]

Adapun untuk lebih jelas aktivitas, uraian dan target tiap kegiatan bisa dilihat pada tabel 1.

Tabel 1. Aktivitas penelitian dengan Waterfall Model

\begin{tabular}{|c|c|c|c|}
\hline Fase & Aktivitas & Keterangan & Target Output \\
\hline \multirow[t]{2}{*}{1} & Persiapan \& & Persiapan dan pengumpulan data & List kebutuhan \\
\hline & Requirements & $\begin{array}{l}\text { dan literatur tentang pemilihan } \\
\text { berbasis online }\end{array}$ & $\begin{array}{l}\text { bahasa pemrograman dan } \\
\text { tool yang dibutuhkan }\end{array}$ \\
\hline \multirow[t]{3}{*}{2} & Design & Membuat desain dan algoritma & Pembuatan Rancangan \\
\hline & & dengan UML atau Flowchart & Aplikasi berbentuk Dokumen \\
\hline & & & Use Case dan Data Alir \\
\hline
\end{tabular}




\section{3}

Development

$4 \quad$ Testing (Pengujian)

Pengkodean dengan bahasa pemrograman ASP Net VB Net Testing Fungsionalitas

\section{Testing Akurasi}

5 Deployment

6 Maintenance \& Training
Pemasangan aplikasi pada hosting dan domain yang telah ditentukan

Pelatihan terhadap pengguna dan pemasangan aplikasi pada hosting dan domain yang telah ditentukan

Aplikasi Pemilihan Online
berbasis Web
Performance terhadap fungsi
dan fitur dari aplikasi
Performance akurasi
terhadap input data user
Pemahaman pengguna dan
Link Aplikasi e-Voting
Pemahaman pengguna dan
panduan penggunaan
aplikasi

Aplikasi Pemilihan Online Performance terhadap fungsi dan fitur dari aplikasi Performance akurasi terhadap input data user Pemahaman pengguna dan Link Aplikasi $e$-Voting panduan penggunaan aplikasi

\section{HASIL DAN PEMBAHASAN}

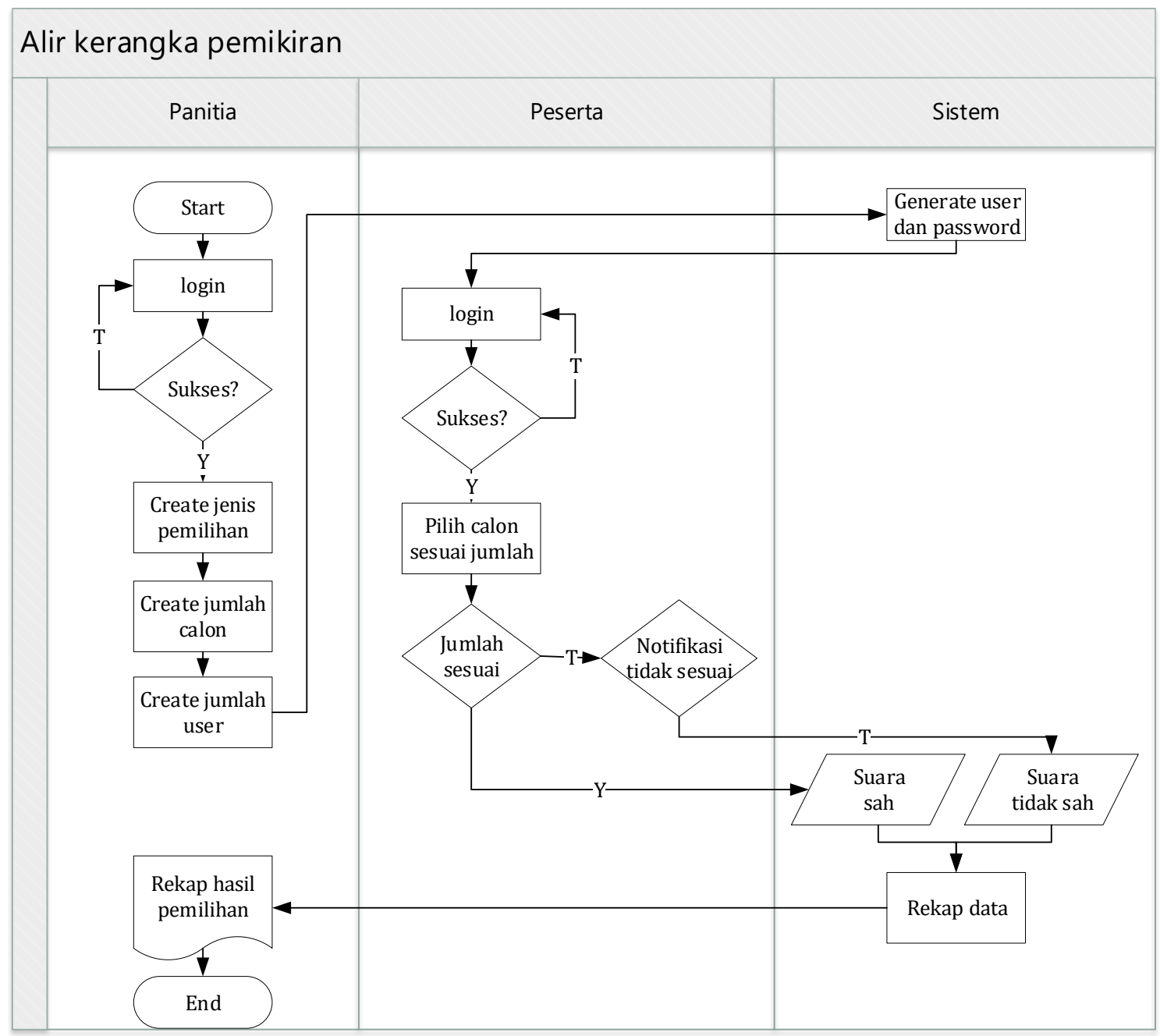

Gambar 2. Rancangan flowchart E-Voting

Berdasarkan metode yang digunakan, berikut adalah tahapan aktivitas secara detail dari masing-masing proses:

\subsection{Persiapan \& Requirements}


Pada tahapan ini dilakukan observasi dan wawancara kepada beberapa pihak dalam hal ini Panitia Pelaksana pemilihan untuk mendapatkan data sebagai sumber kebutuhan untuk pengolahan. Adapun tools yang akan digunakan untuk perancangan dan coding adalah Visual Studio ASP VB.Net dengan Database SQL Server[2].

\subsection{Design}

Untuk mempermudah proses pengembangan aplikasi maka diperlukan Flowchart sebagai kerangka awal untuk mempermudah proses perancangan dan pemrograman. Tahapan berikutnya dibutuhkan relasi antar tabel. Hal ini guna membuat aplikasi yang handal dan database yang normal dan baik. Berikut adalah rancangan ERD yang dibuat:

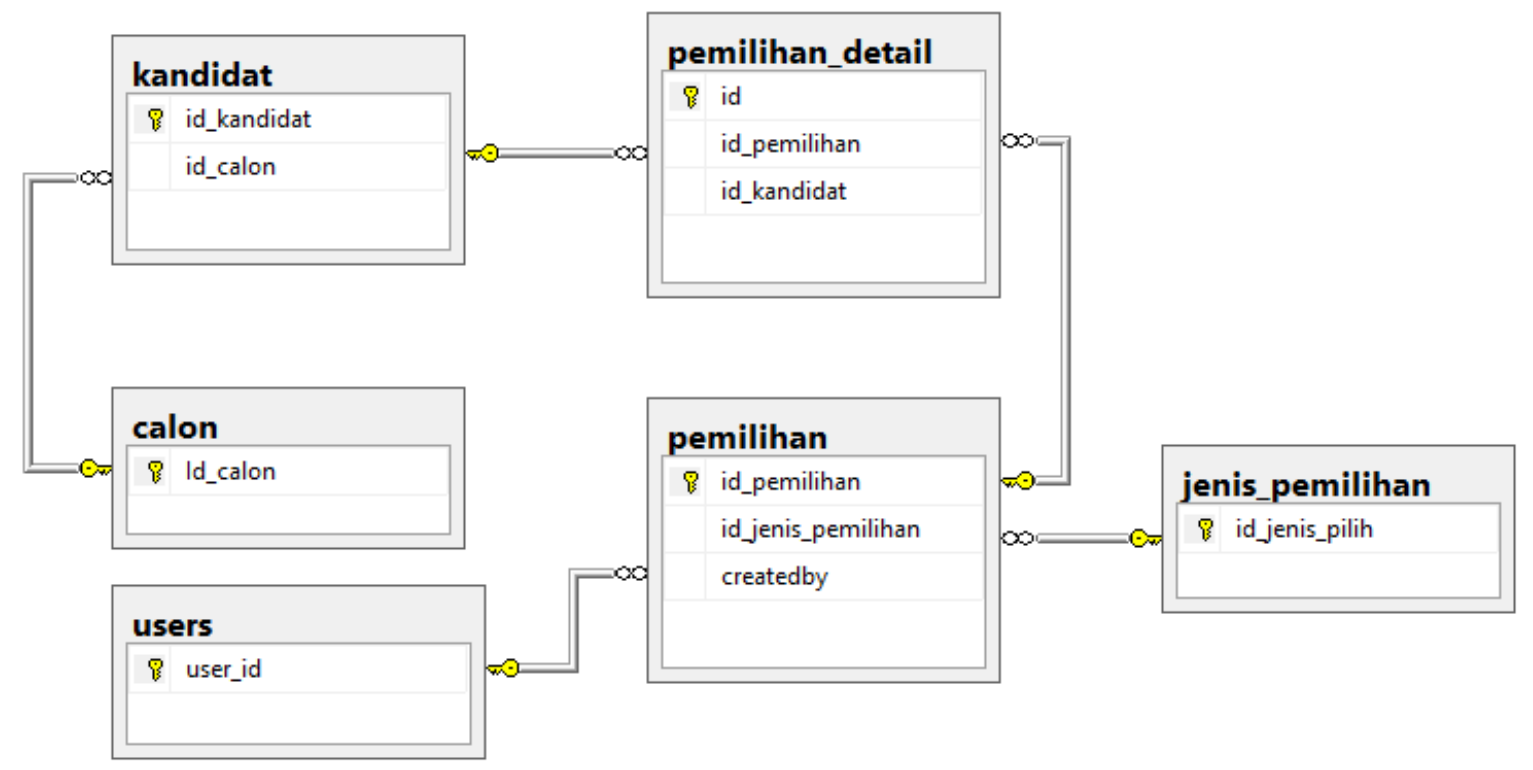

Gambar 3. Rancangan Entity Relationship Diagram (ERD) E-Voting

Tahapan berikutnya adalah melakukan rancangan database dimulai dengan pembuatan tabel berdasarkan kebutuhan.

\begin{tabular}{|l|l|l|}
\hline \multicolumn{1}{|c|}{ Column Name } & \multicolumn{1}{c|}{ Data Type } & Allow Nulls \\
\hline user_id & int & $\square$ \\
\hline user_name & varchar(50) & $\square$ \\
\hline full_name & varchar(100) & $\square$ \\
\hline password & varchar(100) & $\square$ \\
\hline role & varchar(50) & $\square$ \\
\hline isLogin & bit & $\square$ \\
\hline createdby & int & $\square$ \\
\hline createddate & datetime & $\square$ \\
\hline updatedby & int & $\square$ \\
\hline updateddate & datetime & $\square$ \\
\hline & & \\
\hline
\end{tabular}

Gambar 4. Rancangan Database SQL Server - tabel Users

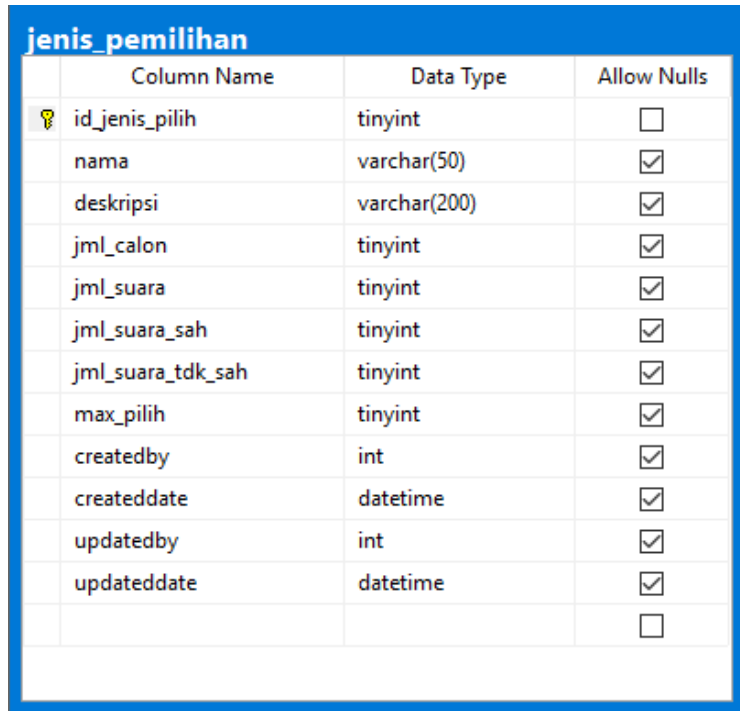

Gambar 5. Rancangan database SQL Server tabel jenis pemilihan 


\begin{tabular}{|c|c|c|c|}
\hline & Column Name & Data Type & Allow Nulls \\
\hline \multirow[t]{5}{*}{8} & id & int & $\square$ \\
\hline & id_pemilihan & int & $\nabla$ \\
\hline & id_kandidat & int & $\nabla$ \\
\hline & isSahd & bit & $\nabla$ \\
\hline & & & $\square$ \\
\hline
\end{tabular}

Gambar 6. Rancangan Database SQL Servertabel pemilihan detail

\begin{tabular}{|l|l|c|}
\hline \multicolumn{1}{|c|}{ Kandidat } & \multicolumn{1}{c|}{ Column Name } & \multicolumn{1}{c|}{ Allow Nulls } \\
\hline B id_kandidat & int & $\square$ \\
\hline no_urut & tinyint & $\square$ \\
\hline id_jenis_pemilihan & tinyint & $\square$ \\
\hline id_calon & int & $\square$ \\
\hline createdby & int & $\square$ \\
\hline createddate & datetime & $\square$ \\
\hline updatedby & int & $\square$ \\
\hline updateddate & datetime & $\square$ \\
\hline & & $\square$ \\
\hline
\end{tabular}

Gambar 7. Rancangan Database SQL Servertabel kandidat

\begin{tabular}{|c|c|c|c|}
\hline \multicolumn{4}{|c|}{ pemilihan } \\
\hline & Column Name & Data Type & Allow Nulls \\
\hline \multirow[t]{10}{*}{8} & id_pemilihan & int & $\square$ \\
\hline & suara_ke & int & $\square$ \\
\hline & id_jenis_pemilihan & tinyint & $\nabla$ \\
\hline & jml_suara & tinyint & $\square$ \\
\hline & isSah & bit & $\square$ \\
\hline & createdby & int & $\square$ \\
\hline & createddate & datetime & $\square$ \\
\hline & updatedby & int & $\square$ \\
\hline & updateddate & datetime & $\nabla$ \\
\hline & & & $\square$ \\
\hline
\end{tabular}

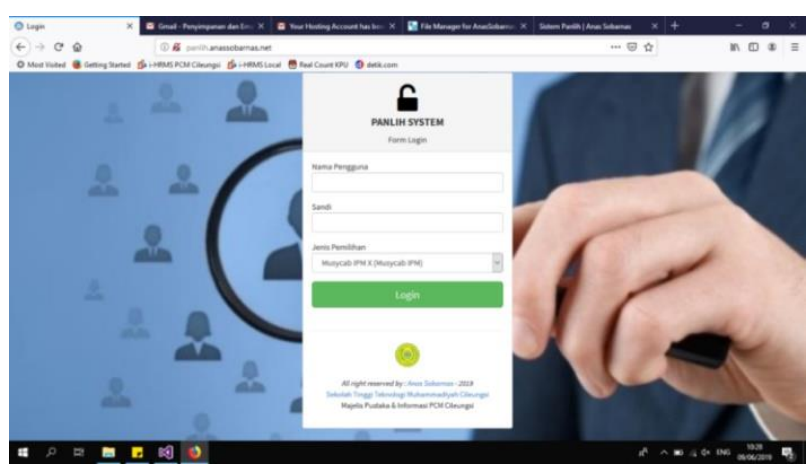

Gambar 9. Rancangan Form - Login

Gambar 8. Rancangan Database SQL Server tabel pemilihan

\subsection{Development}

Langkah selanjutnya adalah membuat design form, berikut adalah tampilan beberapa form yang dibuat menggunakan aplikasi Visual Studio Asp VB.Net:

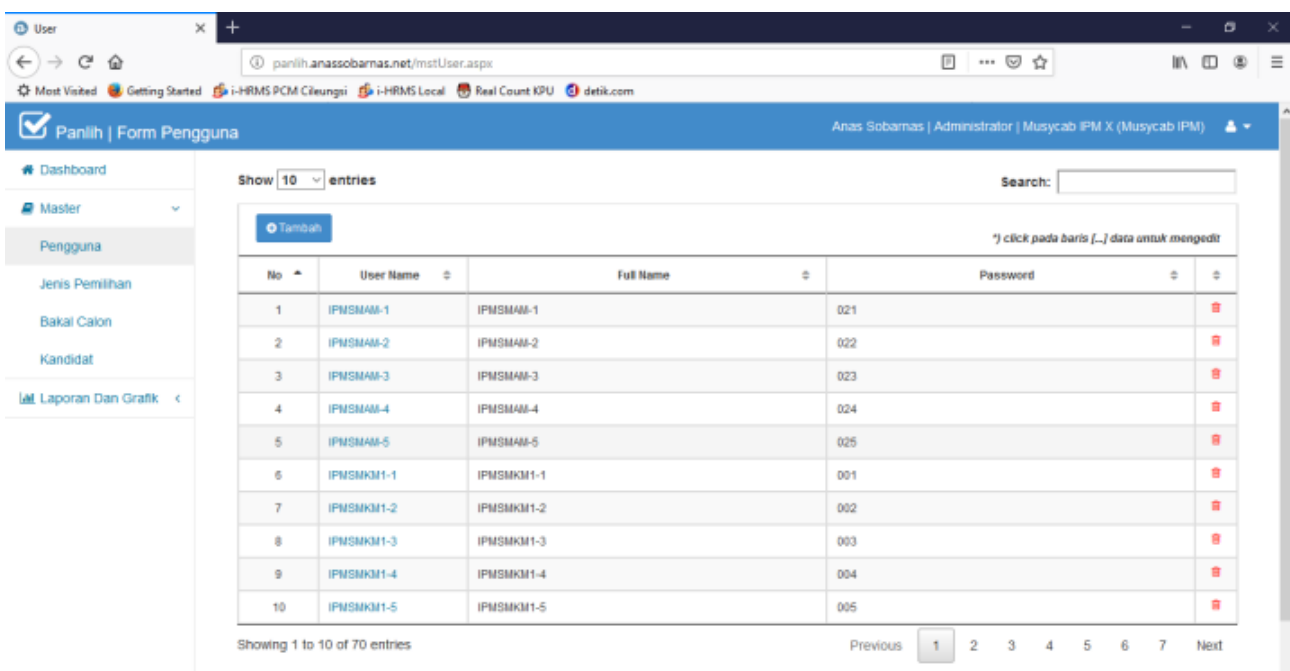




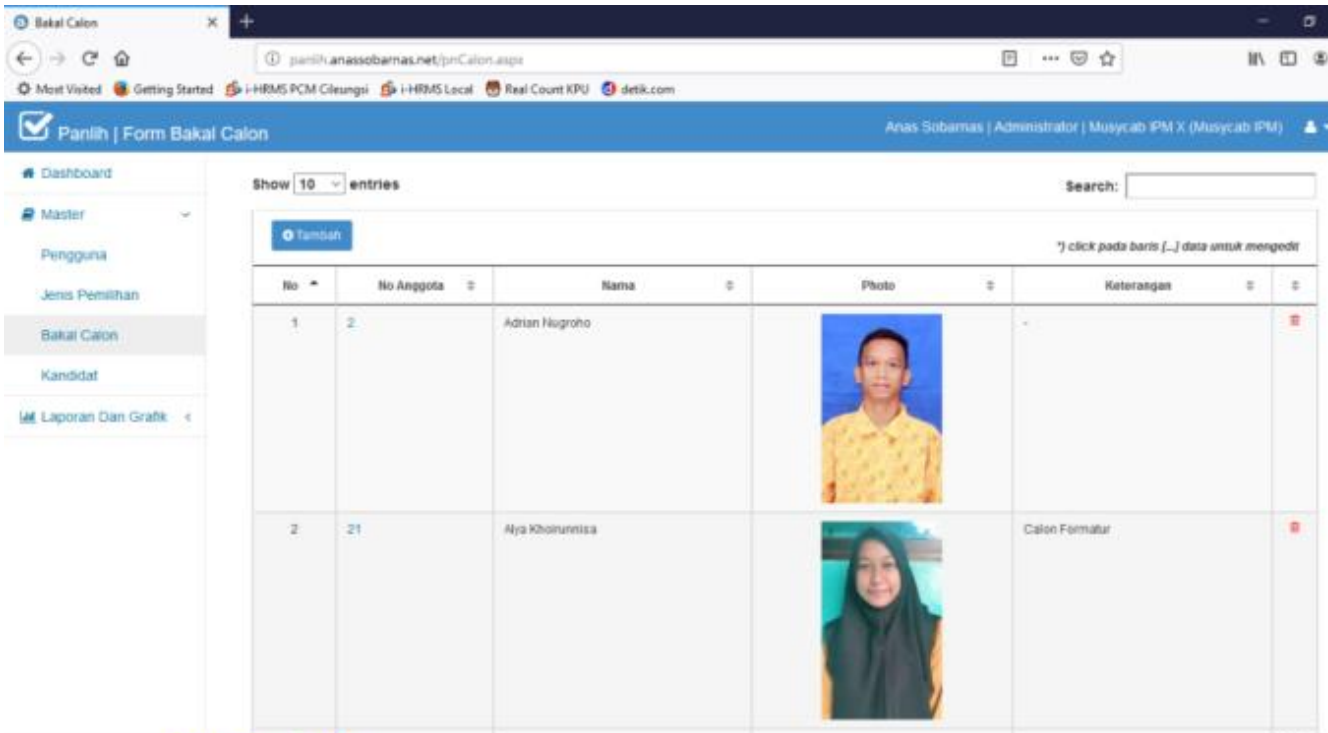

* \&

Gambar 11. Rancangan form-bakal calon

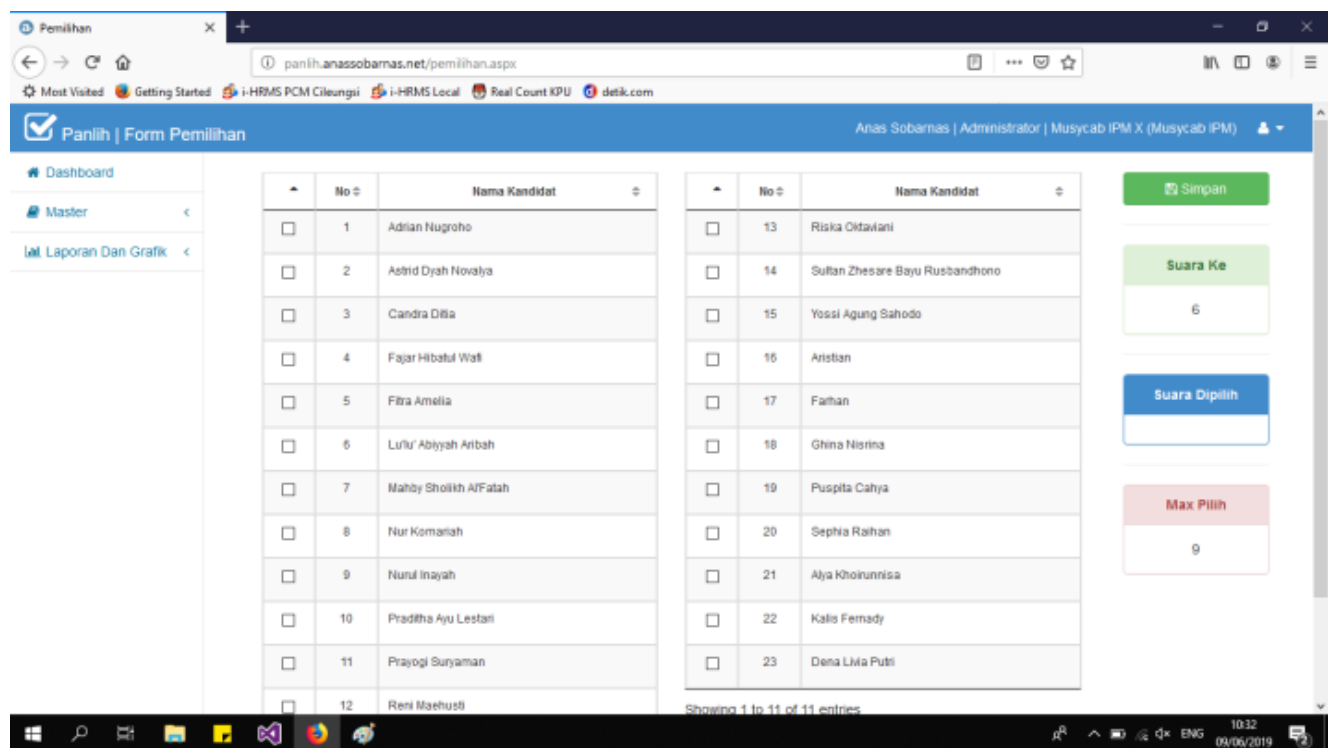

Gambar 12. Rancangan form-proses pemilihan

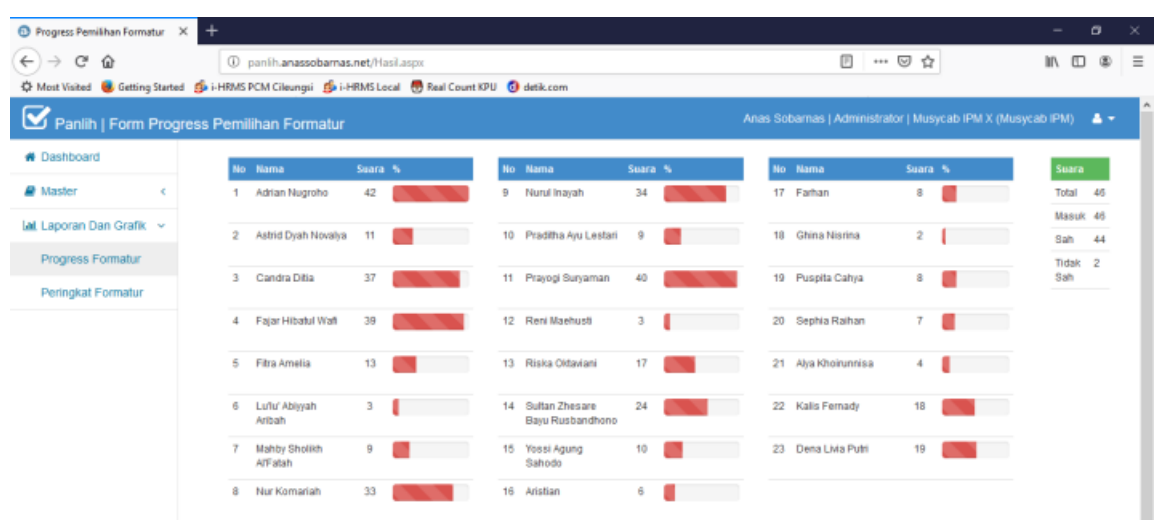

Gambar 13. Rancangan form-progress pemilihan 


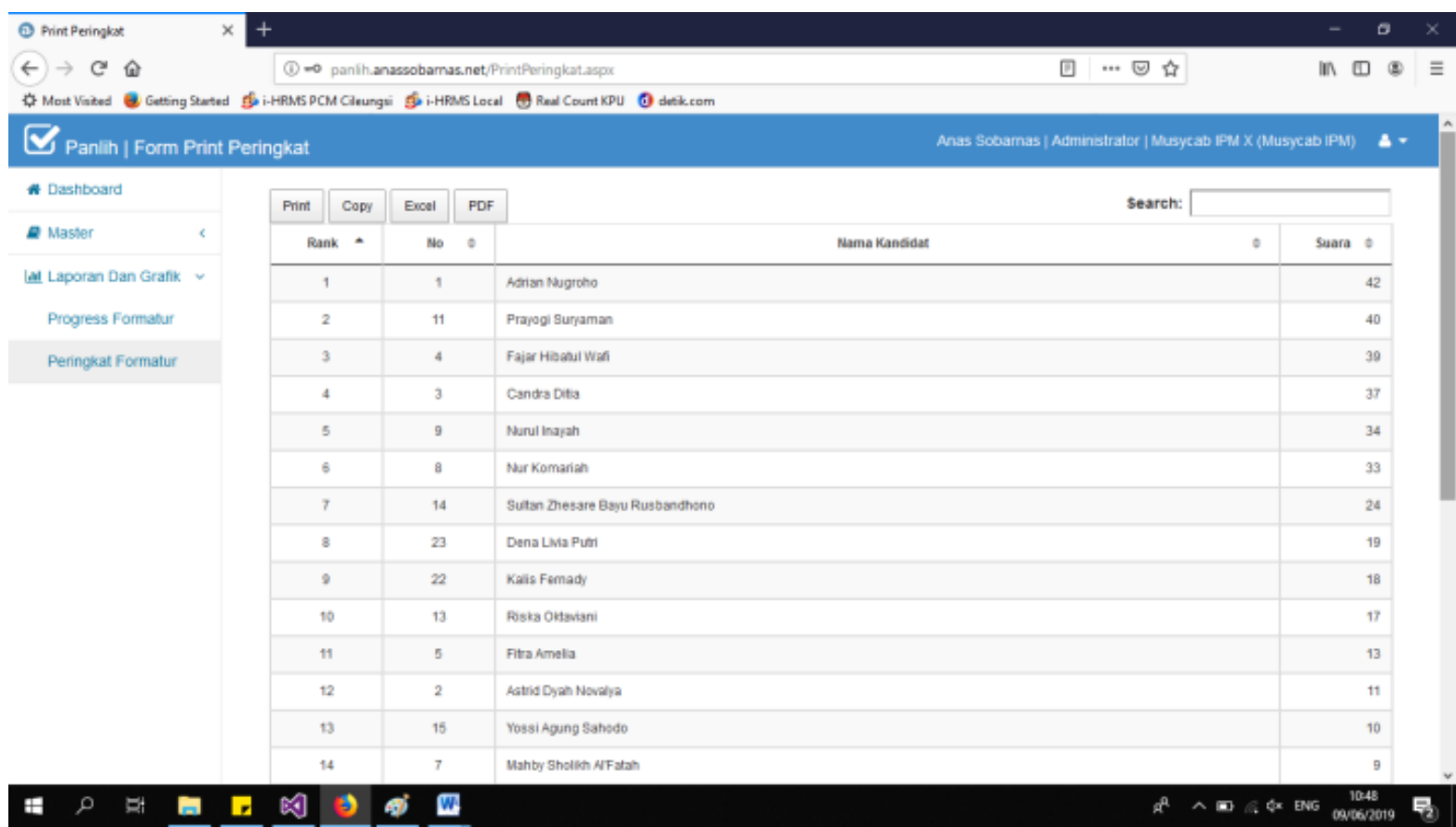

Gambar 14. Rancangan form-report peringkat hasil.

\subsection{Testing (Pengujian)}

Tahapan berikutnya adalah pengujian. Pengujian dilakukan dengan dua tahap, pertama dilakukan pengujian internal oleh team untuk menangkap lebih awal bugs dalam aplikasi. Tahapan kedua dilakukan oleh pengguna (sampling) yang telah diberikan lembar isian kuisioner. Berikut adalah kuesioner kepuasan pengguna yang harus diisi oleh pengguna.

Kuisioner Kepuasan Pengguna
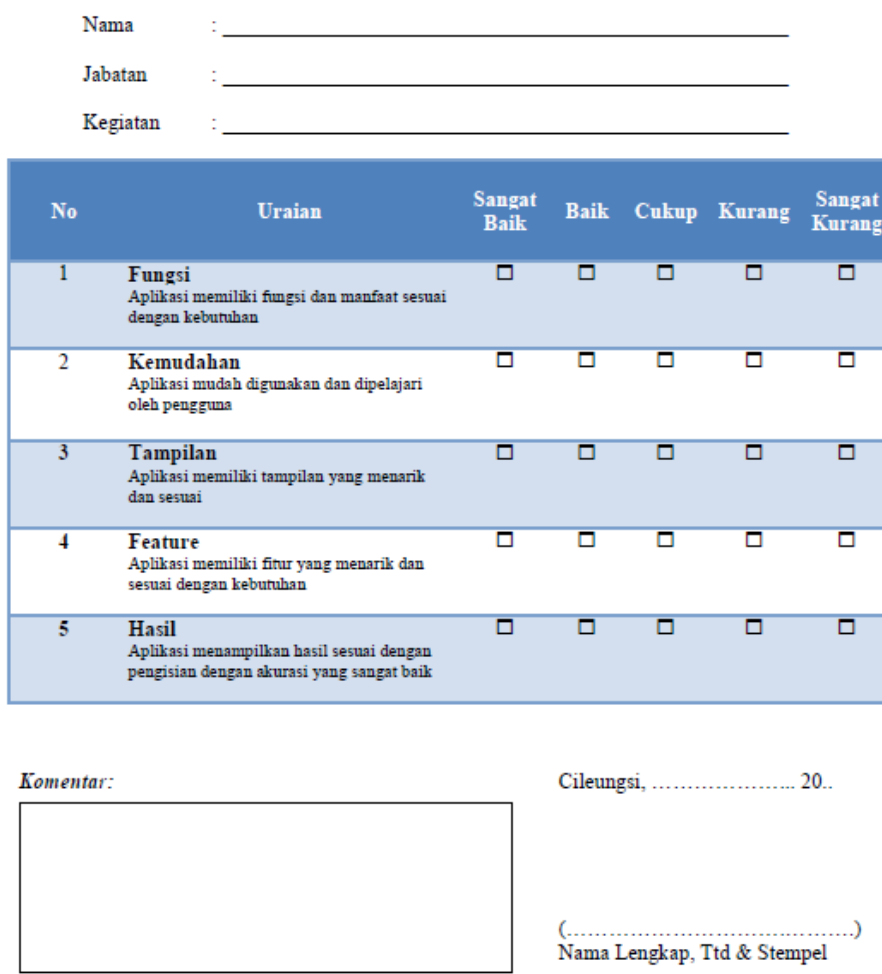

Gambar 15. Form kuisioner kepuasan pengguna 
Berikut adalah hasil isian kuisioner dari para pengguna aplikasi E-Voting pada acara Musyawarah Cabang Pemuda Muhammadiyah Cileungsi:

Tabel 2. Hasil kuisioner kepuasan pengguna aplikasi

\begin{tabular}{|c|c|c|c|c|c|c|}
\hline No & Uraian & $\begin{array}{l}\text { Sangat } \\
\text { Baik }\end{array}$ & Baik & Cukup & Kurang & $\begin{array}{l}\text { Sangat } \\
\text { Kurang }\end{array}$ \\
\hline \multirow[t]{2}{*}{1} & Fungsi & & & & & \\
\hline & $\begin{array}{l}\text { Aplikasi memiliki fungsi dan manfaat } \\
\text { sesuai dengan kebutuhan }\end{array}$ & 10 & 0 & & & \\
\hline \multirow[t]{2}{*}{2} & Kemudahan & & & & & \\
\hline & $\begin{array}{l}\text { Aplikasi mudah digunakan dan } \\
\text { dipelajari oleh pengguna }\end{array}$ & 9 & 1 & & & \\
\hline \multirow[t]{2}{*}{3} & Tampilan & & & & & \\
\hline & $\begin{array}{l}\text { Aplikasi memiliki tampilan yang } \\
\text { menarik dan sesuai }\end{array}$ & 4 & 6 & & & \\
\hline \multirow[t]{2}{*}{4} & Feature & & & & & \\
\hline & $\begin{array}{l}\text { Aplikasi memiliki fitur yang menarik } \\
\text { dan sesuai dengan kebutuhan }\end{array}$ & 3 & 7 & & & \\
\hline \multirow[t]{2}{*}{5} & Hasil & & & & & \\
\hline & $\begin{array}{l}\text { Aplikasi menampilkan hasil sesuai } \\
\text { dengan pengisian dengan akurasi } \\
\text { yang sangat baik }\end{array}$ & 9 & 1 & & & \\
\hline
\end{tabular}

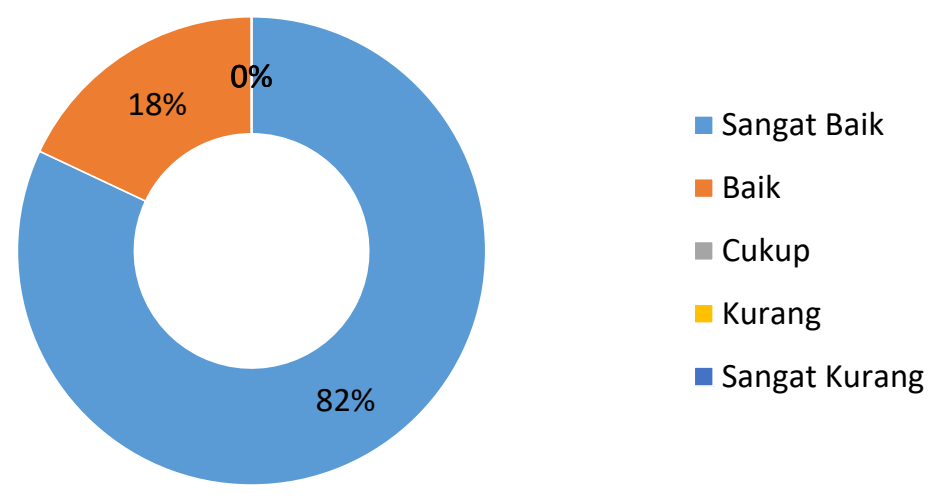

Gambar 16. Pie Chart persentase kepuasan pengguna

\subsection{Deployment}

Langkah berikutnya adalah deployment, aplikasi berbasis web yang telah dibuat di publish atau diposting pada hosting dan domain yang telah ditentukan. Hal ini dilakukan dengan tujuan agar mudah diakses setiap saat.

\subsection{Maintenance \& training}

Tahapan akhir dari proses ini adalah maintenance dan training, perawatan dilakukan secara berkala dengan melakukan pengecekan pada server hosting dan aplikasi. Adapun training dilakukan kepada pengguna bar. Untuk mempermudah proses training juga dibuatkan panduan penggunaan aplikasi bagi pengguna. 


\section{SIMPULAN}

Penelitian ini telah menghasilkan rancangan aplikasi software monitoring bahan baku pada perusahaan pengolahan rempah-rempah dengan menggunakan metode kuantitatif deskriptif yang telah digambarkan menggunakan perancangan UML (Unified Modeling Language). Rancangannya sendiri terdiri dari rancangan use case diagram, rancangan activity diagram permintaan barang, rancangan sequence diagram permintaan bahan baku, rancangan antarmuka (interface), rancangan form cek bahan baku dan perancangan konseptual class diagram. Hasil penelitian ini masih perlu diimplementasikan ke dalam bahasa pemrograman dan menjadi sebuah aplikasi software yang siap digunakan untuk memonitor ketersediaan dan kesesuaian bahan baku sehingga dapat diuji kelayakannya. Oleh karena itu aplikasi software monitoring bahan baku perlu dikembangkan untuk memenuhi kebutuhan semua departemen terkait agar menjadi sistem yang bekerja (working system) sehingga dapat mendukung proses bisnis perusahaan. Selanjutnya pemrogram dapat menggunakan rancangan sebagai dasar pembuatan (pemrograman) aplikasi tersebut.

\section{DAFTAR PUSTAKA}

[1] A. Rokhman, "PROSPEK DAN TANTANGAN PENERAPAN E-VOTING DI INDONESIA," J. Iran. Chem. Soc., vol. 15, no. 8, pp. 1785-1800, 2018, doi: 10.1007/s13738-018-1376-1.

[2] Hendri, "Peningkatan Kapasitas Oven Di Lini PRODUKSI Electodeposition Studi Kasus : DI PT. XYZ," vol. XI, no. 2, pp. 166-175, 2018.

[3] A. T. Muharram, "ANALISIS KINERJA SERVER CLA (CENTRAL LEGITIMIZATION AGENCY) PADA SISTEM E-VOTING PILKADA KOTA BOGOR," J. Tek. Inform., vol. 8, no. 2, 2015, doi: 10.15408/jti.v8i2.2402.

[4] E. Priyono and F. N. Dihan, "E-Voting: Urgensi Transparansi \&amp; Akuntabilitas," Semin. Nas. Inform. Yogyakarta, vol. 2010, no. 32, pp. 55-62, 2010.

[5] L. Hardjaloka and V. Simarmata, "E-Voting: Kebutuhan Vs. Kesiapan (Menyongsong) EDemokrasi," J. Konstitusi, vol. 8, no. 4, pp. 579-604, 2011, doi: 10.31078/jk.

[6] W. Bokslag and M. de Vries, "Evaluating e-voting: theory and practice," 2016.

[7] P. Transfer, D. Pada, A. P. I. Untuk, A. E. Menggunakan, and A. Rsa, "Pengamanan Transfer Data Pada Api Untuk Aplikasi E-Voting Menggunakan Algoritma Rsa,” vol. 3, no. 4, pp. 47$53,2020$.

[8] S. N. Neyman, M. F. Isnaini, and S. Nurdiati, "Penerapan Sistem E-Voting pada Pemilihan Kepala Daerah di Indonesia (The Application of E-Voting Systems in the Local Elections in Indonesia)," J. Sains Terap., vol. 3, no. 1, pp. 35-49, 1970, doi: 10.29244/jstsv.3.1.35-49.

[9] S. Falkner, P. Kieseberg, D. E. Simos, C. Traxler, and E. Weippl, "E-voting authentication with QR-codes," Lect. Notes Comput. Sci. (including Subser. Lect. Notes Artif. Intell. Lect. Notes Bioinformatics), vol. 8533 LNCS, pp. 149-159, 2014, doi: 10.1007/978-3-31907620-1_14.

[10] W. Wijaya and A. Adriansyah, "ANALISIS PEMANFAATAN TEKNOLOGI QR CODE PADA SISTEM ELECTRONIC VOTING (E-VOTING) UNTUK PEMILIHAN KEPALA DAERAH," J. Edukasi Elektro, vol. 4, no. 2, 2020, doi: 10.21831/jee.v4i2.35451.

[11] D. P. Hidayatullah1, R. I. Rokhmawati², and A. R. Perdanakusuma3, "Analisis Pemetaan Pelanggan Potensial Menggunakan Algoritma K-Means dan LRFM Model Untuk Mendukung Strategi Pengelolaan Pelanggan (Studi Pada Maninjau Center Kota Malang)," vol. 2, no. 8, pp. 2548-964, 2018.

[12] MAHMOOD ZAKI ABDULLAH, "DESIGN AND IMPLEMENTATION AN E-VOTING SYSTEM 
Rancang Bangun Aplikasi E-Voting Multi Instansi berbasis Web dengan QR Code

BASED ON SOPHISTICATED TECHNOLOGIES OF WIRELESS NETWORKS AND VISUAL PROGRAMMING LANGUAGES," Int. J. Comput. Networking, Wirel. Mob. Commun. (IJCNWMC, vol. 4, no. 2, pp. 159-172, 2014.

[13] A. koniyo Kusrini, Tuntunan Praktis Membangun Sistem Informasi Akuntansi dengan Visual Basic dan Microsoft SQL Server. Yogyakarta: ANDY, 2007.

[14] A. Buchori, P. Setyosari, I. Wayan Dasna, and S. Ulfa, "Mobile augmented reality media design with waterfall model for learning geometry in college," Int. J. Appl. Eng. Res., vol. 12, no. 13, pp. 3773-3780, 2017.

[15] Sumardiono and Mus Mulyadi Maulana, "PERANCANGAN APLIKASI PESAN TANDING FUTSAL DENGAN METODE WATERFALL," INFOTECH J. Inform. Teknol., vol. 2, no. 1, 2021, doi: 10.37373/infotech.v2i1.107. 